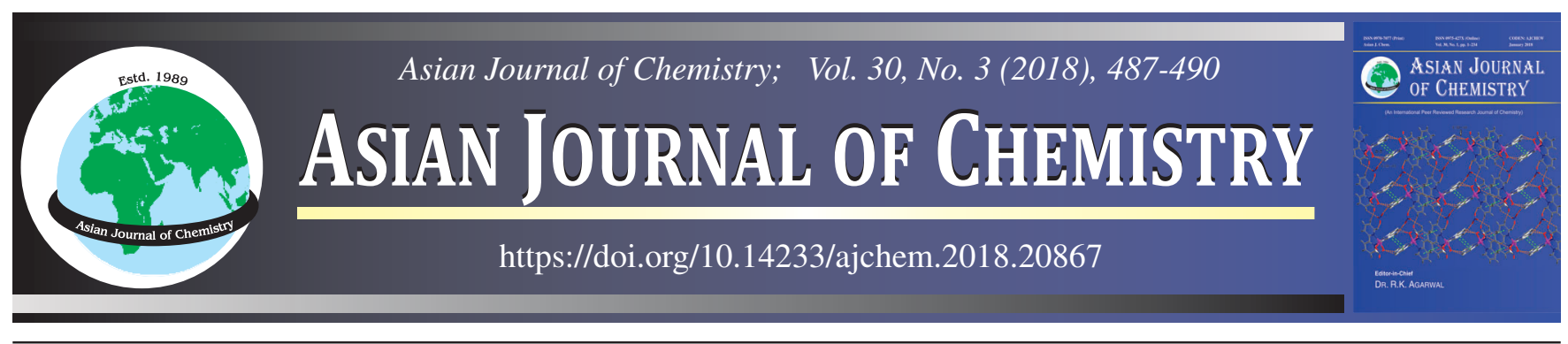

\title{
Comparative Study of Chemical Profiles of Leaf, Root and Seed Essential Oils of Clausena anisata (Willd.) Hook
}

\section{Larayetan Rotimi $^{1,2, *}$, Awodi Patience Ilecholubo ${ }^{3}$, Omobola O. OKoh $^{1}$ and Anthony I. Okoh ${ }^{4,5}$}

${ }^{1}$ Department of Pure and Applied Chemistry, University of Fort Hare, Alice 5700, South Africa

${ }^{2}$ Department of Chemistry, Kogi State University. Kogi State, Anyigba, Nigeria

${ }^{3}$ Department of Biochemistry, Kogi State University, Anyigba, Nigeria

${ }^{4}$ SAMRC Microbial Water Quality Monitoring Center, University of Fort Hare, Eastern Cape, South Africa

${ }^{5}$ Applied and Environmental Microbiology Research Group (AEMREG), Department of Biochemistry and Microbiology, University of Fort Hare, Eastern Cape, South Africa

*Corresponding author: E-mail: timlarayetan@gmail.com

| Clausena anisata (Rutaceae) leaf, root and seed essential oils from Nigeria were obtained by hydro distillation using Clevenger apparatus The oils were analyzed by means of gas chromatography and gas chromatography-mass spectrometry. Eighty-one components were identified in the three plant parts. The oil yields were $0.8 \%$ (leaf), $0.5 \%$ (root) and $1.25 \%$ (seed) v/w of the wet sample. The leaf oil reveals the presence of 26 components accounting for about $99.91 \%$ of the whole volatiles. Sesquiterpenoids hydrocarbons are the most abundant (45.31\%), followed by hydrocarbon (42.03\%), oxygenated sesquiterpenoids $(4.86 \%)$ and oxygenated monoterpenoids $(2.87 \%)$. The major constituents in the leaf oil were 8-methylenedispiro[2.1.2.4] undecane (25.96\%), aromandendrene (14.90\%), germacrene D $(12.98 \%)$. Other notable constituents found are $\beta$-farnesene (5.59\%), patchoulane (3.84\%), $\beta$-bisabolene $(3.37 \%)$ and bisabol $(3.24 \%)$. Forty-five components were detected and identified in the root essential oil amounting to about $99 \%$ of the whole volatiles and is characterized by large presence of sesquiterpenoids hydrocarbon $(62.69 \%)$ followed by monoterpenoids hydrocarbon (10.69\%), oxygenated monoterpenoids $(8.01 \%)$ and oxygenated sesquiterpenoids $(7.39 \%)$. The most abundant components are caryophyllene $(19.21 \%)$, Z- $\beta$ farnesene $(11.18 \%)$, aromandedrene $(9.89 \%)$, $\beta$-bisabolene $(8.12 \%)$ and (+)-nerolidol (4.56 \%). In the seed essential oil, 21 compounds were identified accounting for about $99.76 \%$ of the whole volatiles. The most abundant class of terpenoids are the oxygenated sesquiterpenoids $(26.41 \%)$, followed by monoterpenoids hydrocarbon $(26.07 \%)$. The main components of the seed essential oil are exaltone $(26.41 \%)$, limonene $(9.72 \%)$, oxirane tetradecyl $(8.80 \%)$, 4-methylcyclopentadecanone $(8.80 \%)$, trans- $\beta$-ocimene $(6.16 \%)$ and $1 \mathrm{R}-\alpha$-pinene $(6.15 \%)$.

Keywords: Clausena anisata, Essential oil, GC-MS, Rutaceae, Hydrodistillation.

\section{INTRODUCTION}

Clausena anisata (Willd.) Hook, is also called horse wood or maggot killer, They belong to the Rutaceae family, they are deciduous shrubs or small tree growing up to 4-10 m tall, the bark is smooth, grey-green in colour but becomes brownish and mottled with age [1]. It grows in the savannah or forest region of West Africa including Nigeria and Ghana. It is locally known and called 'Agbasa' by the Yoruba people of Nigeria [2]. The small white flowers have orange-yellow stamens [3]. The fruit are sweet and readily eaten by people and other animals.

The leaves, roots and seeds possess a pleasant odour on account of the essential oil and it's mainly used as a multipurpose folk medicine. The various parts of these plants have been reported to be useful and effective against various ailment and diseases such as parasitic infections, especially flatworm infections, such as schistosomiasis, as well as in influenza, eye complaints and other respiratory ailments, heart disorder and hypertension; abdominal cramps; gastroenteritis and constipation, malaria, diabetics, pyrexia and fever, hepatic disease causing bad breath, rheumatism, boils, arthritis and other inflammatory conditions, headaches, toothaches, body pains, swollen gums, convulsion, mental disorders, impotencies [3-11].

A mixture of C. anisata; Antraegle paniculata and Azadirachtha indica is taken against gut disturbance in Nigeria and a concoction of the later called Agbo is used as antimalaria [3].

Traditional practitioner uses $C$. anisata against oral candidiasis and fungal infection of the skin in Tanzania [4]. It is also used against epilepsy and as an anticonvulsant in Temeke 
district of Darussalam; Tanzania [5]. C. anisata leaves are applied against high blood pressure in South Africa and some parts of Africa and Philippines burn the fresh leaves to obtain smokes used to repel mosquitoes [10]. The chemical composition of the leaves of this plant has been well studied. The leaf essential oils have been reported to consist of methylchavicol (estragole), $\rho$-anisaldehyde, anethole, trans- $\beta$-ocimene and caryophyllene as the major constituents $[6,12]$.

Constituents of volatile oil had been the subject of several studies and various data from literature shows that it has no constancy neither with respect to the components or their percentage. The impact of environmental factors such as relative humidity, harvesting time and method of extraction, location, irradiance, photoperiod, soil structure and climate heavily influence the composition and quality of volatile oils [13]. It is on the basis stated above that led us to investigate the leaf, root and seed essential oil of $C$. anisata grown in Nigeria.

\section{EXPERIMENTAL}

The fresh matured leaves, roots and the seeds of $C$. anisata were collected from their natural habitat at the back of the premises of Kogi State University. Plant identification was done in the department of Botany, Kogi State University Anyigba. Voucher specimens were deposited in the herbarium of the Faculty of biological Sciences, Kogi State University Anyigba, Nigeria.

Oil isolation: $500 \mathrm{~g}$ of the fresh leaves, $150 \mathrm{~g}$ of the root and $250 \mathrm{~g}$ of the seeds were hydro distilled separately for $4 \mathrm{~h}$ using an all glass Clevenger apparatus according to European Pharmacopoeia (2008). Oils were collected and kept in the refrigerator without further treatment before GC-MS analysis.

Characterization: The chemical composition of the essential oil was analyzed using multi-dimensional gas chromatography coupled with gas chromatography-mass spectrometry (Shimadzu GC-MS-QP2010 PLUS, Japan) equipped with a non-polar and polar double capillary columns $(25 \mathrm{~m} \times 0.25 \mathrm{~mm}$, film thickness $0.25 \mu \mathrm{m}$ ). $1.0 \mu \mathrm{L}$ of the oil sample was injected using the split mode (split ratio 100:1) into GC and GC-MS using AOC20i auto injector for analysis. For GC/MS detection, an electron ionization system with ionization energy of $70 \mathrm{eV}$ was used and the mass scanning range was $40-700 \mathrm{~m} / \mathrm{z}$. High purity Helium $(99.99 \%$ ) was used as the carrier gas at a flow rate of $0.99 \mathrm{~mL} / \mathrm{min}$. The initial column temperature for the GC was set at $60^{\circ} \mathrm{C}$, heated at a rate of $3{ }^{\circ} \mathrm{C} / \mathrm{min}$ to $250^{\circ} \mathrm{C}$ and held isothermally for $3 \mathrm{~min}$, the pressure was set at $56.2 \mathrm{Kpa}$; column flow at $0.99 \mathrm{~mL} / \mathrm{min}$ and linear velocity of the column was $36.2 \mathrm{~cm} / \mathrm{sec}$. Ion source temperature of the GC-MS for these analyses was $200{ }^{\circ} \mathrm{C}$, solvent cut time was $3 \mathrm{~min}$. Each peak was then analyzed and assigned a number in the order that it was detected. The identification of the components was based on comparison of their retention indices with those of literature and further identification was made by comparison of their mass spectra with those of NIST library mass spectra database.

\section{RESULTS AND DISCUSSION}

The essential oil of $C$. anisata plant parts (leaf, root and seed) was investigated for its chemical components, the volatile oil imparted pleasant aromatic odour. The GC and GC-MS analyses of the essential oils hydro distilled from the leaf, root and seed of medicinal C. anisata plant from Nigeria produced a pale, clear and light-yellowish colour and revealed the presence of 81 components. The oil yield were $0.8 \%$ (leaf), $0.5 \%$ (root) and $1.25 \%$ (seed) v/w of the wet sample. The chemical constituents identified by GC-MS were listed in order of their retention index, percentage composition, molecular formula and components as shown in Table-1. The leaf oil reveals the presence of 26 components accounting for about $99.91 \%$ of the whole volatiles. Sesquiterpenoids hydrocarbons are the most abundant (45.31\%), followed by hydrocarbon (42.03\%), oxygenated sesquiterpenoids (4.86\%) and oxygenated monoterpenoids $(2.87 \%)$. The major constituents in the leaf oil were 8-methylenedispiro[2.1.2.4] undecane (25.96\%), aromandendrene $(14.90 \%)$, germacrene D $(12.98 \%)$. Other notable constituents found are $\beta$-farnesene ( $5.59 \%$ ), patchoulane (3.84 $\%), \beta$-bisabolene $(3.37 \%)$ and bisabol $(3.24 \%)$.

Forty-five components were detected and identified in the root essential oil amounting to about $99.0 \%$ of the whole volatiles and is characterized by a large presence of sesquiterpenoids hydrocarbon $(62.69 \%)$ followed by monoterpenoids hydrocarbon (10.69\%), oxygenated monoterpenoids (8.01\%) and oxygenated sesquiterpenoids (7.39\%). The most abundant components are caryophyllene $(19.21 \%)$, Z- $\beta$-farnesene $(11.18 \%)$, aromandendrene $(9.89 \%), \beta$-bisabolene $(8.12 \%)$, (+)-nerolidol (4.56\%) and Z, E- $\alpha$-farnesene ( $4.37 \%)$.

In the seed essential oil, 21 compounds were identified accounting for about $99.76 \%$ of the whole volatiles. The most abundant class of terpenoids are the oxygenated sesquiterpenoids $(26.41 \%)$, followed by monoterpenoids hydrocarbon $(26.07 \%)$. The main components of the seed essential oil are exaltone $(26.41 \%)$, limonene $(9.72 \%)$, oxirane tetradecyl $(8.80 \%)$, 4-methylcyclopentadecanone $(8.80 \%)$, trans- $\beta$ ocimene $(6.16 \%)$ and IR- $\alpha$-pinene $(6.15 \%)$. Other notable compounds in the seed essential oil are cis-13-octadecenal $(5.27 \%)$ and methyl-11-octadecanoate (4.12\%). Comparing the components of essential oils in the three plant parts of $C$. anisata (leaf, root and seed) trans- $\beta$-ocimene was the only component common to it, artemesiatriene, aromandendrene, $\beta$-farnesene, caryophyllene and $\beta$-bisabolene were the constituents found in both leaf and root essential oil while $1 \mathrm{R}-\alpha-$ pinene and limonene were both found in the essential oils of the root and seeds.

There was a difference in the earlier report $[6,12]$ on $C$. anisata leaf essential oil of South West and North Central Nigeria grown samples which was reported to be composed of methyl chavicol (estragole), $\rho$-anisaldehyde, anethole, trans$\beta$-ocimene and caryophyllene as the major constituents. In contrast the major components of the leaf essential oil of Nigerian grown sample in our study were 8-methylenedispiro [2.1.2.4] undecane (25.96\%), aromandedrene $(14.90 \%)$ and germacrene D (12.98\%). However, the presence of trans- $\beta$ ocimene and caryophyllene in both leave samples $[6,12]$ and this present study sample present an interesting similarity.

Anethole, $\gamma$-cardinene and estragole found in the NorthCentral $C$. anisata leaf oil [12] were not detected in the present leaf, root and seed oils of our samples. The differences observed may be likely due to the impact of environmental factors such 
TABLE-1

CHEMICAL PROFILES OF LEAVES, ROOTS AND SEEDS ESSENTIAL OILS OF Clausena anisata

\begin{tabular}{|c|c|c|c|c|c|c|}
\hline \multirow{2}{*}{ S. No. } & \multirow{2}{*}{$\begin{array}{l}\text { Retention } \\
\text { index }\end{array}$} & \multicolumn{3}{|c|}{ Composition (\%) } & \multirow{2}{*}{ m.f. } & \multirow{2}{*}{ Compound } \\
\hline & & Leaves & Root & Seeds & & \\
\hline 1 & 688 & & 0.50 & & $\mathrm{C}_{7} \mathrm{H}_{10}$ & 2-Methylenebicyclo[2.1.1]hexane \\
\hline 2 & 733 & & 0.159 & & $\mathrm{C}_{7} \mathrm{H}_{10}$ & 1,3-Dimethylenecyclopentane \\
\hline 3 & 804 & & 0.15 & & $\mathrm{C}_{7} \mathrm{H}_{10}$ & 1,3-Cycloheptadiene \\
\hline 4 & 863 & & & 2.44 & $\mathrm{C}_{9} \mathrm{H}_{14}$ & 3-Methylene-1,7-octadiene \\
\hline 5 & 896 & 0.37 & 0.19 & & $\mathrm{C}_{10} \mathrm{H}_{16}$ & Artemesiatriene \\
\hline 6 & 910 & & & 0.97 & $\mathrm{C}_{9} \mathrm{H}_{12}$ & 8-Methylenebicyclo[4.2.0]oct-2-ene \\
\hline 7 & 934 & & 0.42 & & $\mathrm{C}_{10} \mathrm{H}_{16}$ & 1,2-Diisopropenylcyclobutane \\
\hline 8 & 943 & & 1.29 & 3.07 & $\mathrm{C}_{10} \mathrm{H}_{16}$ & Bicyclo[3.1.1]hept-2-ene, 2,6,6-trimethyl \\
\hline 9 & 948 & & 2.57 & 6.15 & $\mathrm{C}_{10} \mathrm{H}_{16}$ & 1R- $\alpha$-Pinene \\
\hline 10 & 958 & & 1.32 & & $\mathrm{C}_{10} \mathrm{H}_{16}$ & Ocimene \\
\hline 11 & 976 & 0.74 & 3.89 & 6.16 & $\mathrm{C}_{10} \mathrm{H}_{16}$ & trans- $\beta$-Ocimene \\
\hline 12 & 993 & & 0.20 & & $\mathrm{C}_{10} \mathrm{H}_{16}$ & Octatriene, dimethyl- \\
\hline 13 & 997 & 0.47 & & & $\mathrm{C}_{9} \mathrm{H}_{14}$ & 1-Cyclohexyl-1-propyne \\
\hline 14 & 1011 & & & 0.97 & $\mathrm{C}_{10} \mathrm{H}_{14}$ & 1,9-Decadiyne \\
\hline 15 & 1018 & & 0.42 & 9.72 & $\mathrm{C}_{10} \mathrm{H}_{16}$ & Limonene \\
\hline 16 & 1023 & & 0.20 & & $\mathrm{C}_{10} \mathrm{H}_{16}$ & 4-Methyl-3-(1-methylethylidene)-1-cyclohexene \\
\hline 17 & 1052 & & 0.19 & & $\mathrm{C}_{10} \mathrm{H}_{16}$ & Terpinolene \\
\hline 18 & 1067 & 0.78 & & & $\mathrm{C}_{12} \mathrm{H}_{18}$ & 11-Methylene-tricyclo[4.3.1.1(2,5)]undecane \\
\hline 19 & 1067 & 0.78 & & & $\mathrm{C}_{12} \mathrm{H}_{18}$ & 11-Methylene-tricyclo[4.3.1.1(2,5)]undecane \\
\hline 20 & 1076 & & 0.15 & & $\mathrm{C}_{11} \mathrm{H}_{16}$ & 3-Methyl-3,4-divinyl-1-cyclohexene \\
\hline 21 & 1092 & & 0.15 & & $\mathrm{C}_{11} \mathrm{H}_{16}$ & 1-Methyl-5,6-divinyl-1-cyclohexene \\
\hline 22 & 1115 & 12.90 & & & $\mathrm{C}_{12} \mathrm{H}_{18}$ & 1-(1-Ethylvinyl)-1-(2-methylene-3-butenyl)cyclopropane \\
\hline 23 & 1116 & 0.37 & & & $\mathrm{C}_{9} \mathrm{H}_{14} \mathrm{O}$ & Bicyclo[3.3.0]octan-2-ol, 7-methylene \\
\hline 24 & 1122 & & 0.63 & & $\mathrm{C}_{11} \mathrm{H}_{18}$ & Bicyclo[5.1.0]octane \\
\hline 25 & 1125 & & 0.20 & & $\mathrm{C}_{15} \mathrm{H}_{24}$ & (+)-Cycloisosativene \\
\hline 26 & 1136 & & 0.63 & & $\mathrm{C}_{10} \mathrm{H}_{16} \mathrm{O}$ & Verbenol \\
\hline 27 & 1148 & 1.92 & & & $\mathrm{C}_{12} \mathrm{H}_{18}$ & 1-Methyl-2-methylene-3,5-divinylcyclohexane \\
\hline 28 & 1150 & & & 0.98 & $\mathrm{C}_{9} \mathrm{H}_{14} \mathrm{O}$ & 3-Cyclohexene-1-propanal \\
\hline 29 & 1152 & 0.36 & & & $\mathrm{C}_{9} \mathrm{H}_{14} \mathrm{O}$ & cis-8-Hydroxy-bicyclo $(4,3,0)$ non-3-ene \\
\hline 30 & 1169 & & 0.65 & & $\mathrm{C}_{10} \mathrm{H}_{18} \mathrm{O}$ & 6-Methyl-2-vinyl-5-hepten-1-ol \\
\hline 31 & 1174 & & 1.63 & & $\mathrm{C}_{10} \mathrm{H}_{16} \mathrm{O}$ & $\beta$-Citral \\
\hline 32 & 1177 & & 0.20 & & $\mathrm{C}_{10} \mathrm{H}_{15} \mathrm{Br}$ & 1-Bromo-2,2,3,3-tetramethyl-1-(1-propynyl)cyclopropane \\
\hline 33 & 1180 & & 0.65 & & $\mathrm{C}_{10} \mathrm{H}_{18} \mathrm{O}$ & cis-Myrtanol \\
\hline 34 & 1187 & 0.47 & & & $\mathrm{C}_{10} \mathrm{H}_{14} \mathrm{O}$ & Spiro[bicyclo[3.3.0]octan-6-one-3-cyclopropane] \\
\hline 35 & 1215 & 25.96 & & & $\mathrm{C}_{12} \mathrm{H}_{18}$ & 8-Methylenedispiro[2.1.2.4]undecane \\
\hline 36 & 1221 & & 0.99 & & $\mathrm{C}_{15} \mathrm{H}_{24}$ & Copaene \\
\hline 37 & 1228 & 1.62 & & & $\mathrm{C}_{10} \mathrm{H}_{18} \mathrm{O}$ & Isogeraniol \\
\hline 38 & 1251 & & 0.20 & & $\mathrm{C}_{13} \mathrm{H}_{2} \mathrm{O}$ & Bicyclo[2.2.1]heptane, 2-cyclopropylidene-1,7,7-trimethyl \\
\hline 39 & 1302 & & 1.96 & & $\mathrm{C}_{12} \mathrm{H}_{20} \mathrm{O}$ & 9-Methyl-5-methylene-8-decen-2-one \\
\hline 40 & 1318 & & & 0.98 & $\mathrm{C}_{12} \mathrm{H}_{18}$ & Spiro[2.9]dodeca-4,8-diene \\
\hline 41 & 1326 & & 0.63 & & $\mathrm{C}_{10} \mathrm{H}_{1 \mathrm{~m} 8} \mathrm{O}_{2}$ & 1,7,7-Trimethylbicyclo[2.2.1]heptane-2,5-diol \\
\hline 42 & 1328 & 0.46 & & & $\mathrm{C}_{9} \mathrm{H}_{15} \mathrm{NO}_{2}$ & (2-Nitro-2-propenyl)cyclohexane \\
\hline 43 & 1331 & & 0.88 & & $\mathrm{C}_{10} \mathrm{H}_{18} \mathrm{O}_{2}$ & 5-(1-Hydroxy-1-methylethyl)-2-methyl-2-cyclohexen-1-ol \\
\hline 44 & 1344 & 2.35 & & & $\mathrm{C}_{15} \mathrm{H}_{24}$ & $\alpha$-Bourbonene \\
\hline 45 & 1348 & & 0.21 & & $\mathrm{C}_{12} \mathrm{H}_{20} \mathrm{O}_{2}$ & $\beta$-Terpinyl acetate \\
\hline 46 & 1349 & 0.78 & & & $\mathrm{C}_{10} \mathrm{H}_{14} \mathrm{O}_{2}$ & 4-Oxatricyclo $[4.3 \cdot 1.1(3,8)]$ undecan-5-one \\
\hline 47 & 1359 & & 0.63 & & $\mathrm{C}_{12} \mathrm{H}_{18} \mathrm{O}_{2}$ & 2-Heptenoic acid, 7-(methylenecyclopropyl)-, methyl ester \\
\hline 48 & 1386 & 14.90 & 9.89 & & $\mathrm{C}_{15} \mathrm{H}_{24}$ & Aromadendrene \\
\hline 49 & 1393 & 3.84 & & & $\mathrm{C}_{15} \mathrm{H}_{26}$ & Patchoulane \\
\hline 50 & 1403 & & 1.75 & & $\mathrm{C}_{15} \mathrm{H}_{24}$ & $\alpha$-Longipinene \\
\hline 51 & 1430 & & 2.62 & & $\mathrm{C}_{15} \mathrm{H}_{24}$ & trans-alpha-Bergamotene \\
\hline 52 & 1440 & 5.59 & 11.18 & & $\mathrm{C}_{15} \mathrm{H}_{24}$ & $\beta$-Farnesene \\
\hline 53 & 1446 & & 3.70 & & $\mathrm{C}_{15} \mathrm{H}_{24}$ & $\beta$-Sesquiphellandrene \\
\hline 54 & 1452 & & 4.68 & & $\mathrm{C}_{14} \mathrm{H}_{22}$ & 11,11-Dimethyl-spiro[2,9]dodeca-3,7-dien \\
\hline 55 & 1458 & & 4.37 & & $\mathrm{C}_{15} \mathrm{H}_{24}$ & $\alpha$-Farnesene \\
\hline 56 & 1461 & & & 2.06 & $\mathrm{C}_{11} \mathrm{H}_{20} \mathrm{O}_{2}$ & Sevinon \\
\hline 57 & 1468 & & 1.63 & & $\mathrm{C}_{13} \mathrm{H}_{22} \mathrm{O}$ & 4-(2,2-Dimethyl-6-methylenecyclohexyl) butanal \\
\hline 58 & 1471 & & & 2.00 & $\mathrm{C}_{13} \mathrm{H}_{24} \mathrm{O}_{2}$ & Methyl 11-dodecenoate \\
\hline 59 & 1494 & 1.92 & 19.21 & & $\mathrm{C}_{15} \mathrm{H}_{24}$ & Caryophyllene \\
\hline 60 & 1500 & 3.73 & 8.12 & & $\mathrm{C}_{15} \mathrm{H}_{24}$ & $\beta$-Bisabolene \\
\hline 61 & 1509 & & 0.87 & & $\mathrm{C}_{12} \mathrm{H}_{19} \mathrm{NO}$ & $\mathrm{N}$-(4,6,6-Trimethylbicyclo[3.1.1]hept-3-en-2-yl)acetamide \\
\hline
\end{tabular}




\begin{tabular}{|c|c|c|c|c|c|c|}
\hline 62 & 1511 & 1.61 & & & $\mathrm{C}_{13} \mathrm{H}_{22} \mathrm{O}$ & 3,5,9-Trimethyl-deca-2,4,8-trien-1-ol \\
\hline 63 & 1515 & 12.98 & & & $\mathrm{C}_{15} \mathrm{H}_{24}$ & Germacrene D \\
\hline 64 & 1530 & 1.62 & & & $\mathrm{C}_{15} \mathrm{H}_{26} \mathrm{O}$ & Viridiflorol \\
\hline 65 & 1564 & & 4.56 & & $\mathrm{C}_{15} \mathrm{H}_{26} \mathrm{O}$ & +/-.-trans-Nerolidol \\
\hline 66 & 1579 & & 0.66 & & $\mathrm{C}_{15} \mathrm{H}_{24}$ & $\alpha$-Caryophyllene \\
\hline 67 & 1580 & & 0.87 & & $\mathrm{C}_{15} \mathrm{H}_{26} \mathrm{O}$ & $\alpha$-Cadinol \\
\hline 68 & 1625 & 3.24 & & & $\mathrm{C}_{15} \mathrm{H}_{26} \mathrm{O}$ & $\alpha$-Bisabolol \\
\hline 69 & 1702 & & & 8.80 & $\mathrm{C}_{16} \mathrm{H}_{32} \mathrm{O}$ & Oxirane, tetradecyl \\
\hline 70 & 1710 & & 1.96 & & $\mathrm{C}_{15} \mathrm{H}_{26} \mathrm{O}$ & cis-Farnesol \\
\hline 71 & 1719 & 0.46 & & & $\mathrm{C}_{13} \mathrm{H}_{20} \mathrm{~N}_{2}$ & 1,1-dicarbonitrile, 1-cyclohexyl-3-methyl- \\
\hline 72 & 1808 & & & 2.64 & $\mathrm{C}_{16} \mathrm{H}_{30} \mathrm{O}$ & Z-11-Hexadecenal \\
\hline 73 & 1811 & & 0.63 & & $\mathrm{C}_{18} \mathrm{H}_{26} \mathrm{O}$ & 1,3-Bis-(2-cyclopropyl,2-methylcyclopropyl)-but-2-en-1-one \\
\hline 74 & 1924 & & & 0.90 & $\mathrm{C}_{19} \mathrm{H}_{32}$ & Z,Z,Z-1,4,6,9-Nonadecatetraene \\
\hline 75 & 1970 & & & 26.6 & $\mathrm{C}_{15} \mathrm{H}_{28} \mathrm{O}$ & Exaltone \\
\hline 76 & 2007 & & & 5.27 & $\mathrm{C}_{18} \mathrm{H}_{34} \mathrm{O}$ & cis-13-Octadecenal \\
\hline 77 & 2031 & & & 8.80 & $\mathrm{C}_{16} \mathrm{H}_{30} \mathrm{O}$ & 4-Methylcyclopentadecanone \\
\hline 78 & 2061 & 0.47 & & 2.63 & $\mathrm{C}_{18} \mathrm{H}_{32} \mathrm{O}$ & 17-Octadecen-14-yn-1-ols \\
\hline 79 & 2085 & & & 4.12 & $\mathrm{C}_{19} \mathrm{H}_{36} \mathrm{O}_{2}$ & Methyl-11-octadecenoate \\
\hline 80 & 2104 & & & 2.63 & $\mathrm{C}_{19} \mathrm{H}_{36} \mathrm{O}$ & 2-Methyl-Z,Z-3,13-octadecadienol \\
\hline 81 & 2483 & & & 2.06 & $\mathrm{C}_{23} \mathrm{H}_{44} \mathrm{O}_{2}$ & Methyl (13E)-13-docosenoate \\
\hline
\end{tabular}

as relative humidity, harvesting time, method of extraction, location, irradiance, photoperiod, soil structure and climate which heavily influence the composition and quality of volatile oils [13].

It is worth mentioning that compounds such as sevinon, exaltone, verbenol, viridiflorol, oxirane tetradecyl, acetemide and patchoulane which were detected in the present study samples have not been reported previously as part of the constituents of the volatile oil of $C$. anisata plant parts.

\section{Conclusion}

The result obtained in this study showed that $C$. anisata possesses essential oils in all parts of the plants and that the oils were qualitatively and quantitatively different. The study represent the comprehensive analysis of the essential oil of C. anisata plants part grown in Nigeria. Exaltone, caryophyllene, $\beta$-farnesene, aromandendrene, germacrene D, limonene, 8-methylenedispiro[2.1.2.4] undecane were the dominant constituent of the leaf, root and seed essential oils of this medicinal plant. trans- $\beta$-Ocimene was found in the leaf, root and seed oils of $C$. anisata grown in Nigeria, artemesiatriene, aromandedrene, $\beta$-farnesene, caryophyllene and $\beta$-bisabolene were the constituents found in both leaf and root essential oil while $1 \mathrm{R}-\alpha$-pinene and limonene were both found in the essen-tial oils of the root and seeds. Further comprehensive work may be needed on the antioxidant; free radical scavenging and antimicrobial potentials of the leaves, root and seeds essential oil of $C$. anisata.

\section{REFERENCES}

1. A. Tchinda, eds.: G.H. Schmelzer and A.F. Gurib, Clausena anisata (Willd.) Hook F. ex. Benth., Prota 11(2): Medicinal Plants/Plantes Medicinales [CD-ROM], Wageningen, Netherland (2011).

2. M.M. Iwu, Handbook of African Medicinal Plants, CRC Press, New York, pp. 164-166 (1993).

3. A.O. Uwaifo, J. Toxicol. Environ. Health, 13, 521 (1984); https://doi.org/10.1080/15287398409530517.

4. O.J. Hamza, C.J. van den Bout-van den Beukel, M.I. Matee, M.J. Moshi, F.H.M. Mikx, H.O. Selemani, Z.H. Mbwambo, A.J.A.M. Van der Ven and P.E. Verweij, J. Ethnopharmacol., 108, 124 (2006); https://doi.org/10.1016/j.jep.2006.04.026.

5. M.J. Moshi, G.A. Kagashe and Z.H. Mbwambo, J. Ethnopharmacol., 97, 327 (2005);

https://doi.org/10.1016/j.jep.2004.11.015.

6. O. Ekundayo, B.O. Oguntimein and F.J. Hammerschmidt, Planta Med., 52, 505 (1986); https://doi.org/10.1055/s-2007-969274.

7. A. Chakraborty, B.K. Chowdhury and P. Bhattacharyya, Phytochemistry, 40, 295 (1995);

https://doi.org/10.1016/0031-9422(95)00047-B.

8. C. Ito, S. Katsuno, M. Itoigawa, N. Ruangrungsi, T. Mukainaka, M. Okuda, Y. Kitagawa, H. Tokuda, H. Nishino and H. Furukawa, J. Nat. Prod., 63, 125 (2000); https://doi.org/10.1021/np990285x.

9. J. Mester, K. Szendrei and J. Reisch, Planta Med., 32, 81 (1977); https://doi.org/10.1055/s-0028-1097563.

10. A.L. Okunade and J.I. Olaifa, J. Nat. Prod., 50, 990 (1987); https://doi.org/10.1021/np50053a046.

11. J.A.O. Ojewole, Phytother. Res., 19, 1023 (2005); https://doi.org/10.1002/ptr.1779.

12. L.A. Usman, A.A. Hamid, N.O. Olawore, C.O. Fakunle, I.A. Oladosu and M.F. Zubair, J. Appl. Sci. Res., 6, 891 (2010).

13. L. Panizzi, G. Flamini, P.L. Cioni and I. Morelli, J. Ethnopharmacol., 39, 167 (1993); https://doi.org/10.1016/0378-8741(93)90032-Z. 